\title{
Standardized Hemorrhagic Shock in Rats after Acute and Chronic Exposure to High Altitude
}

\author{
Pipat Cherdrungsi \\ Department of Physiology, Faculty of Science, Mahidol University, \\ Rama vi Road, Bangkok 10400, Thailand
}

\begin{abstract}
Acute exposure to high altitude for 1 day in rats caused an increase in hematocrit (Hct) with no change in mean arterial blood pressure (mABP) from the non-altitude control, whereas after prolonged exposure to altitude (5-6 weeks) there were increases in both Hct and mABP. No changes in total plasma protein (TPP) and plasma osmolality (POsm) from control rats were observed in all altitude-exposed animals. The ability of the acutely and chronically altitude and non-altitude exposed rats to resist hemorrhage was studied. Hemorrhage was standardized at $\mathrm{mABP}$ in the range of $30-35 \mathrm{mmHg}$. Chronic exposure to altitude increased the initial and maximum volume of blood withdrawn as well as the oligemic and survival times, whereas acute altitude exposure did not. The higher ability to resist standardized hemorrhagic shock of the chronically altitude exposed rats seemed to result, in part, from their greater hemodilution and better arterial blood pressure regulation. No difference in the rate of hemodilution as well as hemorrhagic tolerance was observed between the 1-day altitude and control rats. The difference in rate of hemodilution between the chronic altitude and control animals could not be due to arterial hyperosmolality since the magnitude of change in POsm during blood loss was the same for all animal groups.
\end{abstract}

Key words: acute altitude exposure, chronic altitude exposure, standardized hemorrhage, rats.

It is well established that hemorrhage leads to a condition of shock due to reduction in blood volume in excess of compensation. The techniques developed for producing hemorrhagic shock consistently fall into two general groups, those in which a fixed amount of blood is withdrawn regardless of the changes induced in arterial pressure (STRAwITZ et al., 1961; WIGGERS, 1950), and those in which sufficient blood is withdrawn to maintain mean arterial pressure at a fixed low level (Butcher and Braitberg, 1969; Fell, 1966; Wiggers, 1950). A hemorrhagic study in high altitude exposed animals using the first technique of bleeding, that is with uncontrolled arterial blood pressure, has been performed. It

Received for publication March 8, 1985 
showed that acute exposure to high altitude for one day gave the animals a decreased resistance to blood loss compared with non-altitude animals, whereas chronic exposure to high altitude increased hemorrhagic resistance (CHERDRUNGSI, 1981; Cherdrungsi and Verawatnapakul, 1983). The difference in degree of resistance to blood loss among the animal groups has been found to be dependent on the ability of the animals to regulate their arterial blood pressure. The altitude animals that showed higher ability to resist blood loss exhibited smaller decrements in arterial blood pressure during hemorrhage. However, the characteristics of hemorrhagic resistance of the altitude animals are changed have not been investigated when mean arterial blood pressure is kept constant at a hypotensive level during bleeding. Accordingly, the present study was carried out on acutely and chronically high-altitude exposed and sea level exposed rats subjected to standardized hemorrhage at $30-35 \mathrm{mmHg}$ mean arterial blood pressure. The initial and the maximum blood volume withdrawn to achieve and stabilize the blood pressure and the survival time after blood transfusion were recorded. In addition, changes in hematocrit (Hct), total plasma protein (TPP), and plasma osmolality (POsm) were measured during the hypotensive period.

\section{MATERIALS AND METHODS}

The experiments were conducted in male adult Wistar rats with initial body weights of 150-360 g. Two sets of experiments were performed to study the effects of two different durations of high altitude exposure on resistance to standardized hemorrhage. The animals with high initial body weights were used for the altitude exposure experiments of short duration and those with lower initial body weights for the prolonged altitude exposure experiments.

Altitude animals were weighed and kept in decompression chambers where they were continuously exposed to a simulated altitude of $5,000 \mathrm{~m}$ either acutely ( 1 day) or chronically (5-6 weeks) with food and water ad libitum. Details of the altitude exposure method have been previously reported (CHERDRUNGSI, 1981). The animals in each set were divided into two groups: control and altitude. There were two control groups which represent, respectively, the control animals for the acute and the chronic groups.

At the end of the hypoxic altitude period, the altitude-exposed rats were brought to sea level pressure, weighed, and given the following experimental treatment also given to the corresponding control group. Each rat was anesthetized by intraperitoneal injection of $5 \mathrm{mg}$ vetanarcol per $100 \mathrm{~g}$ body weight. Tracheostomy was performed. Both femoral arteries were cannulated. A 50 unit per $100 \mathrm{~g}$ rat weight dose of heparin was administered $10 \mathrm{~min}$ before bleeding was begun. The experiments were carried out at room temperature $\left(25-27^{\circ} \mathrm{C}\right)$.

The method of inducing hemorrhagic shock employed in these experiments was the constant pressure technique used previously by many investigators 
(Butcher and Braitberg, 1969; Fell, 1966). By this method free bleeding was allowed from one of the cannulated arteries into a reservoir consisting of a $10 \mathrm{ml}$ glass syringe, until blood pressure recorded from the other femoral artery had dropped to $30-35 \mathrm{mmHg}$. The reservoir was connected to a pressure bulb and variations in arterial blood pressure were corrected by changing the air pressure in the reservoir using this bulb. This method enabled blood pressure to be kept constant. When volume of blood loss reached its maximum, re-injection of blood from the reservoir was needed to maintain blood pressure at the designed hypotensive level of $30-35 \mathrm{mmHg}$. This period was terminated in each animal when $30 \%$ of the lost blood had been re-injected. Immediately following this, the rest of the blood still remaining in the reservoir was reinfused at the same speed as the initial withdrawal. Arterial blood pressure was recorded continuously via the polyethylene catheters by means of a strain gauge pressure transducer (Stathum P23 AC, Statham Instruments) and a recorder (Beckman Type R Dynograph). The animals were continuously observed until death and the survival time was recorded. Death was indicated by cessation of breathing and no detectable arterial pressure. The survival time was measured as the duration between the end of blood reinfusion and the time that death ensued.

About 4-6 arterial blood samples, $0.3-0.5 \mathrm{ml}$ each, were taken from the animals for various examinations. One sample was taken during the control period before withdrawal of blood and the other samples were taken during the oligemic period. Each blood sampling entailed the filling of a heparinized microcapillary tube, with the balance being drawn into a $1 \mathrm{ml}$ syringe, via the femoral arterial catheter. Blood was not sampled after the point of maximum blood withdrawal was reached. The sampled blood was not replaced but was taken into account during volume calculation. Blood was not sampled after reinfusion because this might have affected the survival time if the amount of blood volume left in the animals was too low. Blood in the micro-capillary tube was centrifuged with an IEC hematocrit centrifuge (Model MB) for at least $7 \mathrm{~min}$. The blood sample in the $1 \mathrm{ml}$ syringe was transferred to a small glass test tube containing about $0.4-0.7 \mathrm{mg}$ EDTA anticoagulant. The sample was mixed and centrifuged for about $30 \mathrm{~min}$ with an IEC clinical centrifuge (Clinical Model) and plasma was taken for measurement of protein and osmolality. Percent hematocrit was read using an IEC international micro-capillary reader (Model 2201). Total plasma protein was determined colorimetrically at $540 \mathrm{~nm}$ by the Biuret method. Plasma osmolality was determined by a cryoscopic method using an Advanced osmometer (Model 3R).

Statistical evaluation was done by Student's $t$-test. The level of significance was set at the $95 \%$ confidence limit. 


\section{RESULTS}

Changes in some physiological parameters in rats exposed to simulated altitude for 1 day (acute exposure) and 5-6 weeks (chronic exposure) compared with those of the control rats are shown in Table 1. Since there were no significant differences in the measured parameters between the two control groups, both were combined and are presented as a single control for the two altitude groups.

There were no significant differences in body weight (BW) and mean arterial blood pressure (mABP) between the acutely altitude and the non-altitude exposed rats, whereas $\mathrm{BW}$ and $\mathrm{mABP}$ of the chronically altitude exposed rats were respectively lower $(p<0.001)$ and higher $(p<0.02)$ than those of the control animals.

The hematocrits of rats exposed acutely and chronically to high altitude were significantly higher than the control group ( $p<0.001$ for both altitude groups), but total plasma protein (TPP) and plasma osmolality (POsm) of the two altitude groups were not significantly different from those of the control animals.

During the first part of hemorrhage the rats continued to give off blood into the reservoir. The average rate of bleeding during the initial phase of blood with-

Table 1. Physiological parameters of control rats and acutely and chronically altitude exposed rats.

\begin{tabular}{llllcc}
\hline \multicolumn{1}{c}{ Group } & BW $(\mathrm{g})$ & $\begin{array}{c}\mathrm{mABP} \\
(\mathrm{mmHg})\end{array}$ & \multicolumn{1}{c}{ Hct $(\%)$} & $\begin{array}{c}\text { TPP } \\
(\mathrm{g} / \mathrm{dl})\end{array}$ & $\begin{array}{c}\text { POsm } \\
\left(\mathrm{mOsm} / \mathrm{kg} \mathrm{H} \mathrm{H}_{2}\right)\end{array}$ \\
\hline Control (20) & $321 \pm 8$ & $112.7 \pm 2.7$ & $45.6 \pm 0.6$ & $7.1 \pm 0.2$ & $289.9 \pm 4.1$ \\
1-day altitude (10) & $299 \pm 10$ & $119.2 \pm 2.3$ & $52.0 \pm 1.0^{*}$ & $7.2 \pm 0.3$ & $302.5 \pm 6.1$ \\
Chronic altitude (8) & $199 \pm 6^{*}$ & $123.4 \pm 1.6^{*}$ & $62.5 \pm 1.0^{*}$ & $7.4 \pm 0.3$ & $291.9 \pm 6.1$ \\
\hline
\end{tabular}

BW, body weight; $\mathrm{mABP}$, mean arterial blood pressure; Hct, hematocrit; TPP, total plasma protein; POsm, plasma osmolality. Values are mean \pm S.E. The numbers in parentheses indicate the number of rats tested. * Significantly different from the control (at least $p<0.05$ ).

Table 2. Parameters concerning standardized hemorrhage at a constant hypotension level of $30-35 \mathrm{mmHg}$ in rats.

\begin{tabular}{|c|c|c|c|c|c|c|c|c|}
\hline Group & $\begin{array}{c}\text { mABP } \\
\text { at } 30 \\
\text { mmHg } \\
(\% \text { original })\end{array}$ & $\begin{array}{c}\text { Speed } \\
\text { of } \\
\text { bleeding } \\
(\mathrm{ml} / \mathrm{min})\end{array}$ & $\begin{array}{c}\text { Initial } \\
\text { blood } \\
\text { withdrawn } \\
(\mathrm{ml} / \mathrm{kg})\end{array}$ & $\begin{array}{l}\text { Maximum } \\
\text { blood } \\
\text { loss } \\
(\mathrm{ml} / \mathrm{kg})\end{array}$ & $\begin{array}{c}\text { Oligemic } \\
\text { time } \\
\text { (min) }\end{array}$ & $\begin{array}{l}\text { Time to } \\
\text { max. } \\
\text { blood } \\
\text { loss } \\
\text { (min) }\end{array}$ & $\begin{array}{l}\text { Volume } \\
\text { of } \\
\text { blood } \\
\text { reinfused } \\
\text { (\% max. } \\
\text { blood loss) }\end{array}$ & $\begin{array}{c}\text { Survival } \\
\text { time } \\
(\mathrm{min})\end{array}$ \\
\hline $\begin{array}{c}\text { Control } \\
\text { (20) }\end{array}$ & $\begin{array}{r}26.9 \\
\pm 0.6\end{array}$ & $\begin{array}{r}0.36 \\
\pm 0.03\end{array}$ & $\begin{array}{r}8.6 \\
\pm 0.4\end{array}$ & $\begin{array}{r}26.8 \\
\pm 0.9\end{array}$ & $\begin{array}{r}138.9 \\
\pm 12.1\end{array}$ & $\begin{array}{r}70.2 \\
\pm 4.5\end{array}$ & $\begin{array}{r}33.7 \\
\pm 2.0\end{array}$ & $\begin{array}{r}129.5 \\
\pm 19.1\end{array}$ \\
\hline $\begin{array}{l}\text { 1-day } \\
\text { altitude } \\
\quad(10)\end{array}$ & $\begin{array}{r}25.2 \\
\pm 0.5\end{array}$ & $\begin{array}{r}0.35 \\
\pm 0.03\end{array}$ & $\begin{array}{r}10.7 \\
\pm 1.0\end{array}$ & $\begin{array}{r}25.7 \\
\pm 1.0\end{array}$ & $\begin{array}{r}134.2 \\
\pm 17.1\end{array}$ & $\begin{array}{r}56.2 \\
\pm 7.4\end{array}$ & $\begin{array}{r}35.1 \\
\pm 2.9\end{array}$ & $\begin{array}{r}143.8 \\
\pm 17.3\end{array}$ \\
\hline $\begin{array}{l}\text { Chronic } \\
\text { altitude } \\
\text { (8) }\end{array}$ & $\begin{array}{c}24.3 \\
\pm 0.3^{*}\end{array}$ & $\begin{array}{r}0.45 \\
+0.05\end{array}$ & $\begin{array}{c}15.3 \\
\pm 1.3^{*}\end{array}$ & $\begin{array}{c}32.9 \\
\pm 1.1^{*}\end{array}$ & $\begin{array}{c}240.5 \\
\pm 22.0^{*}\end{array}$ & $\begin{array}{c}98.1 \\
\pm 9.6^{*}\end{array}$ & $\begin{array}{r}33.1 \\
\pm 2.3\end{array}$ & $\begin{array}{c}231.6 \\
\pm 14.0 *\end{array}$ \\
\hline
\end{tabular}

Values are mean \pm S.E. The numbers in parentheses indicate the number of rats tested. * Significantly different from the control (at least $p<0.05$ ). 
drawal (blood volume withdrawn divided by time taken to remove the blood until mean arterial pressure dropped from prehemorrhagic value to a level of $35 \mathrm{mmHg}$ ) was about $0.3-0.4 \mathrm{ml} / \mathrm{min}$ for all animal groups (Table 2). The initial volume of blood withdrawal required to produce standardized hypotension at $35 \mathrm{mmHg}$, the time elapsed to reach maximum blood loss, the maximum volume of the lost blood, and the oligemic time, i.e. the period of time between the start of hypotension of $35 \mathrm{mmHg}$ and the start of blood reinfusion when $30 \%$ of the lost blood had been reinjected, were all comparable in the control rats and the acutely altitude exposed rats; these parameters were higher in the chronically altitude exposed rats than the control animals ( $p<0.001 ; p<0.02 ; p<0.001$; and $p<0.001$, respectively). There was no significant difference in the volume of blood reinfused among all

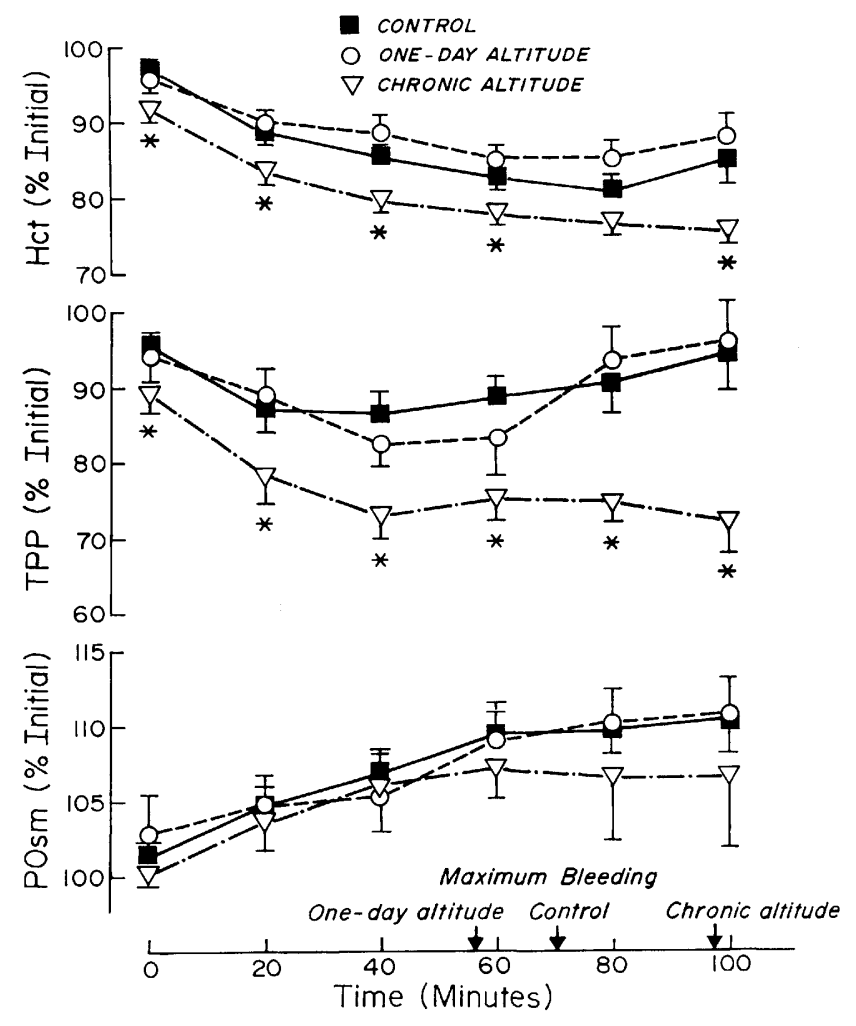

Fig. 1. Percent changes from prehemorrhagic levels of hematocrit (Hct), total plasma protein (TPP), and plasma osmolality (POsm) during the first $100 \mathrm{~min}$ of standardized hemorrhage at mean arterial blood pressure of $30-35 \mathrm{mmHg}$ in control rats and 1-day altitude and chronic altitude exposed rats. Time 0 refers to the starting point of the period of steady state reduced blood pressure. Values are mean +S.E. Arrows indicate the time of maximum blood withdrawal of the three animal groups. An asterisk indicates values significantly different (at least $p<0.05$ ) from the control animals.

Vol. 35, No. 4, 1985 
animal groups since it was about $33-35 \%$ of the maximum blood loss for all of them.

Figure 1 indicates percent changes in hematocrit, total plasma protein, and plasma osmolality of the acutely and chronically altitude exposed and the nonaltitude exposed rats. Immediately after the mean arterial blood pressure reached the level of $35 \mathrm{mmHg}$, the hematocrit and total plasma protein of the control rats were significantly decreased below the prehemorrhagic levels $(97.0 \pm 1.1$ and $95.4 \pm$ $1.3 \%$, respectively) and decreased further with increasing blood loss. Similar patterns of change in these parameters were observed in the 1-day and the chronic altitude animals. There were no significant differences in the rates of change in these parameters between the control and the 1-day altitude groups, but the rates of change in these two parameters were greater in the chronic altitude rats than the other two groups. At the beginning (time zero) of the oligemic period, the hematocrit and total plasma protein of the chronic altitude rats were $91.6 \pm 0.8$ and $89.0 \pm$ $2.2 \%$ of the prehemorrhagic levels, respectively (Fig. 1). Plasma osmolality of the control group and the 1-day and the chronic altitude groups gradually increased. There was no significant difference in plasma osmolality changes when comparing these three animal groups.

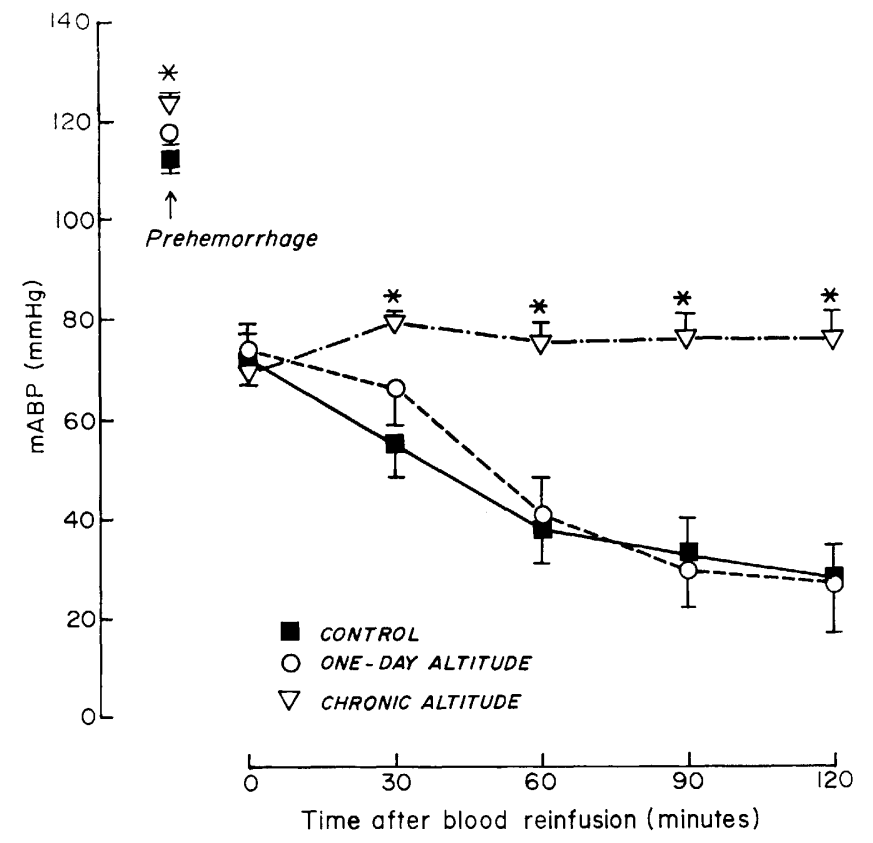

Fig. 2. Mean arterial blood pressure after blood reinfusion in 1-day altitude and chronically altitude exposed rats compared with that in control rats. Time 0 refers to the ending point of blood reinfusion (the starting point of post-infusion period). Values are mean + S.E. Prehemorrhagic values of the three animal groups are also shown. An asterisk indicates values significantly different (at least $p<0.05$ ) from the control animals. 
After the end of blood reinfusion, mABP was increased but remained lower than the prehemorrhagic level and then gradually tapered off to zero at which point the animals were considered dead. The average mean arterial blood pressure within two hours after blood infusion for all animal groups is shown in Fig. 2. The post-infusion blood pressure of the 1-day altitude rats was not significantly different from that of the control rats, whereas the post-infusion mABP of the chronically altitude exposed rats stayed at a higher level than that of the other two groups of animals.

\section{DISCUSSION}

Acute exposure to high altitude in rats for 1 day caused no change in tolerance to standardized hemorrhage at mean arterial blood pressure of $30-35 \mathrm{mmHg}$ at sea level whereas exposure for prolonged periods of 5-6 weeks resulted in an improvement in the hemorrhagic tolerance compared with their non-exposed sea level counterparts. This effect occurred in spite of the fact that a blood pressure of $30 \mathrm{mmHg}$ for this group was about $24 \%$ of the original pressure for the chronically high altitude exposed rats, and about 25 and $27 \%$ for the acutely high altitude and the non-altitude exposed animals, respectively.

No change in resistance to standardized hemorrhage from control was observed in the 1-day altitude rats in many categories such as the initial and the maximum volume of blood withdrawn, the oligemic time, and the survival time. This suggests that the efficiency of physiological compensatory mechanisms of rats in adjustment to standardized hemorrhage at a constant low mean arterial blood pressure was not affected by acute exposure to high altitude. This is suggested by the facts that the rate of decreases in hematocrit (indicating the rate of hemodilution) and the changes in total plasma protein and plasma osmolality during hemorrhage for the 1-day altitude exposed rats were similar to those for the non-altitude exposed animals. Hemodilution is an important mechanism of the cardiovascular compensatory adjustment during bleeding for refilling of the circulatory system. It occurs due to fluid absorption from extravascular space into the vascular bed. Although previous studies have reported that acute exposure to high altitude caused hypohydration in rats (Fregly et al., 1976; PiCON-ReAtegur et al., 1953; SwANN et al., 1942), the results of the present study suggest that such hypohydration of the altitude rats should not be a limiting determinant of the rate of hemodilution during standardized hemorrhage. The similarity in the rates of hemodilution between the 1-day altitude and the non-altitude exposed rats was found to be due to the similar increases in their plasma osmolality during bleeding.

The oligemic time, the time to maximum blood loss, and the survival time for the chronically altitude exposed rats were all longer than their corresponding controls. This suggests that resistance, especially to severe or irreversible hemorrhagic shock, was greater in the chronic altitude animals. The difference in sur- 
vival time between the chronic altitude animals and the control animals should not have been due to the volume of blood reinfused after bleeding, since all animal groups received blood on average about 33 to $35 \%$ of the maximum blood withdrawal and no animal in any group received blood less than $25 \%$. Although the volume of blood reinfused recalculated on the basis of $\mathrm{ml} / \mathrm{kg}$ ((maximum bleeding volume $) \times(\%$ volume of blood reinfusion $) / 100)$ is highest in the chronic altitude group, this might not render an advantage to the chronic altitude animals resulting in an increase in hemorrhagic tolerance since it has been reported that mortality among groups of rats treated with various fractions of the blood removed to produce hypotension does not vary significantly if as much as one fourth of the shed blood is returned to the animals (BUTCHER and BRAITBERG, 1969).

The increase in tolerance to hemorrhagic shock in the chronic altitude rats could not be attributed to the decrease in body weight since it has been recently reported that survival of hemorrhage in rats is poorer for the lighter weight rats (WIEGMAN et al., 1978).

The greater volume of initial and maximum blood withdrawal as well as the longer oligemic and survival time in the chronic altitude rats might be due in part to their greater initial total blood volume and greater ability for regulation of arterial blood pressure during bleeding as has been previously observed in the altitude-acclimatized rats (CHERDRUNGSI, 1981). Higher ability for arterial blood pressure regulation was also observed in the chronically altitude exposed rats at the end of the hypotensive period in the present study. However, whether such higher ability of the chronic altitude rats in maintaining their arterial blood pressure after blood reinfusion can be attributed to cardiac factors or peripheral factors or both is as yet unknown. In addition, the blood volume reinfused should not be a contributing factor for the improved blood pressure control since all animal groups received back about $33-35 \%$ of the maximum blood withdrawal (although the chronic altitude group got back the highest volume of shed blood when calculated on the basis of $\mathrm{ml} / \mathrm{kg}$ as formerly described) and all animal groups exhibited the same level of mean arterial blood pressure immediately after blood reinfusion.

Another important factor responsible for higher resistance to standardized hemorrhage might be indicated by the greater hemodilution which occurred in the chronically altitude exposed animals during blood loss.

The greater degree of hemodilution in the chronically altitude exposed rats indicates that these animals possess a more efficient mechanism for refilling of the circulatory system and thereby for restoring of cardiovascular homeostasis. The drop in hematocrit was found to be associated with an increase in plasma osmolality. Hemorrhagic hyperosmolality has been demonstrated to be an important mechanism in transcapillary osmotic absorption of fluid from the extravascular space (JARHULT et al., 1972; JARHULT, 1973). However, the time courses of change in plasma osmolality of the chronically altitude exposed rats was not significantly different from that of the control. Thus hyperosmolality alone could not account 
for the difference in degree of hemodilution between the animal groups. However, the chronically altitude exposed rats still exhibit greater hemodilution which reflected more fluid absorption from the extravascular into the intravascular space. This suggests that there might be other mechanisms which are more effective than those of the control rats exist in the chronically altitude exposed animals and are responsible for their greater fluid absorption. According to Starling's analysis of forces involving in transcapillary fluid shift, another important mechanism of transcapillary fluid absorption is the transcapillary hydrostatic pressure difference. A reflex adrenergic resetting of the pre-to-postcapillary hydrostatic pressure has been reported to be a factor causing hemodilution during hemorrhage (OBERG, 1964). Although the level of sympathetic activity during bleeding was not measured in the present study, it has been previously reported that the level of sympathetic activity of chronically altitude exposed animals was increased (MAHER et al., 1975). It is possible that the greater hemodilution during hemorrhage in the chronic altitude animals could have been due to a reflex sympathetic control in capillary hydrostatic pressure. In addition, a significantly greater percent decrease in mean arterial blood pressure at $30 \mathrm{mmHg}$ in chronic altitude animals in the present study might also somehow be related to the higher fluid absorption into vascular spaces in this animal group. However, the nature of the mechanisms responsible for this or the specific role of the magnitude of arterial blood pressure change on transcapillary fluid movement is as yet unclear.

In any case, it can be concluded from the present study that exposure to high altitude for 1 day in rats caused no significant change from control in response to standardized hemorrhage at sea level at mean arterial blood pressure of 30-35 $\mathrm{mmHg}$. No significant differences in degree of hemodilution and plasma osmolality were observed among these two animal groups. Chronic exposure to high altitude increased the volumes of both initial and maximum blood withdrawal as well as the oligemic and survival time in rats subjected to standardized hemorrhage. The chronically altitude exposed animals exhibited a more efficient mechanism for refilling of the circulatory system, i.e. a greater hemodilution, during the course of bleeding and a higher ability for arterial blood pressure regulation at the end of the controlled hypotensive period. Arterial hyperosmolality did not correlate with the greater hemorrhagic hemodilution in this study.

This study was supported in part by the National Research Council of Thailand. The author would like to thank Ms. Somporn Phyayongsaksataporn, Dr. Kathleen S. Pang, and Ms. Suthada Homjun for their invaluable help.

\section{REFERENCES}

Butcher, H. R., Jr. and Braitberg, A. (1969) Hemorrhagic shock in rats. Arch. Surg., 98: 685-693.

Cherdrungsi, P. (1981) Tolerance of high altitude acclimatized rats to blood loss at sea level. 
Q. J. Exp. Physiol., 66: 291-296.

Cherdrungsi, P. and Verawatnapakul, V. (1983) Hemorrhagic tolerance of rats at sea level after acute exposure to high altitude. Aviat. Space Environ. Med., 54: 347-350.

FeLl, C. (1966) Changes in distribution of blood flow in irreversible hemorrhagic shock. Am. J. Physiol., 210: 863-868.

Fregly, M. J., Nelson, E. L., Jr., and Tyler, P. E. (1976) Water exchange in rats exposed to cold, hypoxia, and both combined. Aviat. Space Environ. Med., 47: 600-607.

JARHULT, J. (1973) Osmotic fluid transfer from tissue to blood during hemorrhagic hypotension. Acta Physiol. Scand., 89: 213-226.

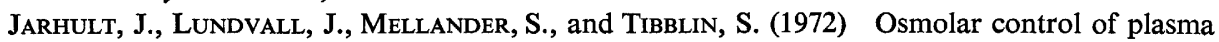
volume during hemorrhagic hypotension. Acta Physiol. Scand., 85: 142-144.

Maher, J. T., Manchanda, S. C., Cymerman, A., Wolfe, D. L., and Hartley, L. H. (1975) Cardiovascular responsiveness to beta-adrenergic stimulation and blockage in chronic hypoxia. Am. J. Physiol., 228: 477-481.

OBerg, B. (1964) Effects of cardiovascular reflexes on net capillary fluid transfer. Acta Physiol. Scand. (Suppl.), 62: 229.

Picon-Reategui, E., Fryers, G. R., Berlin, N. I., and Lawrence, J. H. (1953) Effect of reducing the atmospheric pressure on body water content of rats. Am. J. Physiol., 172: 33-36.

Strawitz, J. G., Hift, H., Temple, R. L., Ehrhardt, A., and Rozansky, N. (1961) Irreversible hemorrhagic shock in rats: method and critical bleeding volume. Am. J. Physiol., 200: 257-260.

Swann, H. G., Collings, W. D., Cline, J. K., and Dernehl, C. U. (1942) Negative water balances following exposures to low barometric pressures. Science, 96: 588-589.

Wiegman, D. L., Harris, P. D., Miller, F. N., Morf, R. J., and Wilmoth, F. R. (1978) Survival and microvascular responses to hemorrhage with three anesthetic combinations. Am. J. Physiol., 235: H753-H758.

Wiggers, C. J. (1950) Physiology of Shock. The Commonwealth Fund, New York, pp. 121146. 